\title{
Maximum Benefits from a Program for Staff Reading
}

Dr. Burton is an instructor in English and has taught in the Developmental Reading Program at Purdue University.

$\mathrm{T}$ HAT LIBRARIANS SHOULD KNOW more about books than their covers and the cards which locate them is easy to see, but it is not always so easy to see how this goal can be achieved. Libraries cannot depend on getting staffs made up only of devoted booklovers or of those determined to keep up with the best of current books; they cannot depend, that is, on the extracurricular ambition of their staffs. But at last the profession is becoming more acutely aware of the problem and is suggesting ways of solving it. Any effort to prevent the disappearance of the well-read librarian is praiseworthy. One of the best of such efforts is that of Robert H. Muller, ${ }^{1}$ who suggests that libraries allow on-the-job time for librarians to read. "What [such a] program would create (he writes) is a staff of librarians who read and who know books and who may thus be in a better position to stimulate reading in others. ... It is the book-steeped atmosphere thus engendered that would also save the soul of many a library employee and encourage others to join the profession." Mr. Muller proceeds to work out the details of the program, which I need not summarize, since his proposals are familiar to the readers of this journal.

1 “A Program for Staff Reading," college AND RESEARCH LIBRARIES, I 4:235-239, July, I 953 .
Mr. Muller's is no doubt the ultimate solution, but the cost of the program as stated (he estimates $\$ 23.55$ per book read) is so exceptionally high that it appears unlikely of adoption in more than one or two farsighted-and wealthy-libraries. But a way is open to reduce the cost by at least $50 \%$, or from $\$ 23.55$ to approximately $\$ 11.78$ per book read. This reduction is possible by increasing the efficiency of the reading; for it can be demonstrated that the average reader can double his reading speed with no loss of comprehension-or perhaps even with a slight gain in comprehension. The forty pages per hour as an estimate of the speed of the average feader of the average book, as cited by Mr. Muller for his calculations of the cost of the program, can be accepted: but when the average reader reads eighty pages per hour instead of forty, the cost is of course reduced by one-half. And since librarians usually have a predisposition in favor of reading, else they would not be librarians, they are probably above-average readers, and many could expect with brief training to triple their reading speed or to make still more exceptional gains. If the staff members participating in Mr. Muller's program, or one like it, could learn to triple their reading speed (and I should not be surprised if they did), the cost would be $\$ 7.85$ per book read. Not only would the cost of the program of staff reading be reduced with the help of a program of developmental reading, but the other reading activities of the staff would 
also be more efficient-their other library tasks as well as the reading they do on their own time.

Mr. Muller's program calls for two hours daily, or about $25 \%$ of staff time, which represents a percentage increase required to pay for the program "of probably less than $13 \%$ of the total budget in public libraries." When the developmental reading program is adopted as a part of the staff reading program, one hour daily should be sufficient to bring the same results, and the cost would be about $6 \%$ of the budget.

In the improvement of reading speeds, I believe, lies the answer to the problem of finding time to be well read. And time to be well read is doubly necessary for librarians if they are to continue to be guides to the insides of books as well as to the outsides, and if, as Mr. Muller says, the profession of librarianship is to continue to attract not the dull, routine, and clerical, but the literate, the well informed, and the judicious.

It is well to say, improve your reading speed two- or three-fold, with no loss of comprehension; but how is it to be done? Fortunately, the method is now, after eight or ten years of research and experiment, well known, and can, I think, be considered almost certain of producing excellent results. ${ }^{2}$ The details of the method and the record of the results are easily available. ${ }^{3}$ Briefly, the method is this: one who wishes to realize more fully his reading potential reads an hour or so several times a week with a pacer ${ }^{4}$ designed to encourage him to

2 The development reading is not to be confused with remedial reading for handicapped readers. Developmen. tal reading programs are designed for average and superior readers.

${ }_{3}$ Among these are Cosper, Russell and Mills, Barriss, "Developmental Reading at Purdue," Journal of Higher Education, 24:258-262, May, 1953; and Kinne, Ernest W., "Reading Improvement for Adults," College Eng. lis., "Reading Improvement for

4 Several types of pacer are available. Among them are the Accelerator (Science Research Associates, Chicago, \$105.67), the Shadowscope (Lafayette Instrument Company, Lafayette, Indiana, $\$ 95.00$ ), and the Rateometer (Audio-Visual Research, Chicago, \$35.00). List prices are given. add gradually to his highest previous speed. If the reader is one of a group, he may also see a series of films ${ }^{5}$ which guide his eye movements rhythmically along a printed text, training him in the technique of better reading. The reader will probably be tested frequently in his speed and comprehension of articles of varying difficulty. If a reader is working alone, ${ }^{6}$ he will give himself essentially the same training except that he will not have access to the films.

And what results can be expected? Published findings vary, of course, with the nature of the instruction and with the abilities and application of the readers; but in three or four months of regular training average readers can expect to double their reading rates and to gain slightly in comprehension. The 608 students in the Developmental Reading Program at Purdue University, for example, in the fall semester of 1953, began with an average reading speed of 222 words per minute, and ended with a speed of 457 words per minute. This is $106 \%$ improvement, or something more than a doubling of the beginning reading speeds. ${ }^{7}$ Comprehension of material read at the beginning was $58 \%$ and of similar material at the end of the term, $70 \%$; so that, far from sacrificing comprehension for speed of reading, there was actually a significant gain. Individual readers, naturally, gained much more in reading speed; and perhaps eight or ten readers out of a hundred read more than Iooo words per minute after two or three months of instruction at two hours each week. An

\footnotetext{
5 Best known is the Harvard University series of seventeen films.

${ }^{6}$ Among the books designed to improve the abilities of a reader working alone as well as the member of a group are: Lewis, Norman. How to Read Better and group are: Lewis, Norman. Howe to Read Better and Faster. rev. ed. N. Y., Crowell, I95I; and Glock, Mar-
vin D. The Improvement of College Reading. Boston, Houghton Mifflin, r 954 .

7 I realize that an increase figured on the basis of "average beginning subtracted from average ending" is different statistically from an average figured on individual gains; but the difference is slight, and in any case the figure for the average of individual gains is not now available.
} 
occasional, gifted reader will improve his reading speed ten-fold with no loss of comprehension.

So much for a brief account of the methods and possibilities of a program to improve reading habits. How can such a program help libraries with their plans for staff reading? The exact method will naturally vary with the facilities of the college or research library. If the library is connected with-an institution which already has a developmental reading program, the library need only arrange to have selected staff members attend the classes. A few staff members, upon completing the program, may wish to continue their reading with a pacer as long as they improve their reading skills. Tests show that most of the increases in reading speeds are retained, even after three or four years, and, with continued reading, the increased speed is presumably retained indefinitely.

Most libraries, however, will not have access to an already established program of developmental reading. A college library will do well, in this case, to enlist the assistance of someone in the Education Department or in the English Department who is familiar with the developmental reading program in order to secure preliminary counsel, or to appoint a member of the staff to investigate the procedure and make recommendations. The procedure when no established program is available is to supply training facilities for the improvement of reading skills on an individual rather than a class basis. Such facilities might be provided in this manner: the library will set aside a room (behind the scenes in comfortable surroundings, as $\mathrm{Mr}$. Muller suggests) for on-the-job reading by participating staff members. A small room of office size will suffice. The room will be equipped with a table and chair, a pacer and book of instructions. ${ }^{8}$ With this mini- mum equipment, a staff member is ready to read. He will spend his first few days familiarizing himself with the principles and methods of reading improvement and with the operation of the pacer. He will set the pacer at a speed slightly too fast for reading comfort and try daily to increase his speed by five or ten percent. Not all the added speed will remain with him, of course, but much of it will; and as he becomes more certain of his reading techniques, his speed will rise more rapidly.

In two or three weeks he will have completed the orientation and the reader will need to refer only occasionally to the instructions for additional suggestions for his reading improvement. He is now free to read, at a steadily increasing rate, the books which are his share of the library staff reading program. He learns to read books of varying difficulty at varying rates of speed. For a few minutes each week he will turn from his reading at the pacer to time his reading of an article and to check his comprehension. These weekly exercises serve as a measure of his progress. Several books have been designed for this purpose. ${ }^{9}$ Reasonable application to this program will soon enable him to read in one hour material which formerly required two or three.

Since each member of the program will use the room for only one hour a day, the room will serve as many members as there are hours in the library day-eight, twelve, or as in a few university libraries, sixteen. And if the library wishes to have its staff members read two hours a week instead of five or six, the number of staff members which can be accommodated in the de-

8 See Lewis or Glock in note 6.

9 Cosper, Russell, and Griffin, E. Glenn, Toward Better Reading Skill, N. Y., Appleton-Century-Crofts, I953, has thirty articles, questions on each article for determining comprehension, problems for further discussion, vocabulary lists, and conversion tables; Perry, William G. cabulary lists, and conversion tables; Perry, William G., and Whitlock, Charles P., Selections for Improving Speed of Comprehension, Cambridge, Harvard Univer-
sity Press, I948, has fifteen articles, questions, and conversion tables. 
velopmental reading room would be doubled or tripled, one shift of staff members reading for an hour on Monday and Thursday, say, and another on Tuesday and Friday. Or, as one set of readers is weaned from the pacer, those readers could use another part of the room, while a second set of readers begins instructions and reading by the pacer. Two hours a week instead of two hours a day would, of course, reduce the cost of the program still further, to about $2 \%$ or $3 \%$ of the total budget ; but Mr. Muller believes that too great a limiting of the time allowed for the reading program will reduce the effectiveness as well as the cost.

It should be remembered that an understanding of ideas is the paramount purpose in reading and that a program of increasing speed is not a race. Members of a developmental reading program are not in competition with each other, but with themselves. A library cannot go into the developmental reading program with an eye chiefly on the money to be saved by making rapid readers of its staff, and should realize that its profits will come primarily from wide and efficient reading by the staff. The staff should not be made to feel that their object in improving reading skills is to save money, as indeed it is not, because however fast the reading is done, the library is still underwriting the program and is simply offering an additional service which will benefit all concerned. Benefits accrue because rapid reading is good reading, and slow reading is poor reading: all records of developmental reading programs I have seen, including those of the program at Purdue for four years, confirm this statement. When a reader is absorbing facts and ideas at top speed, his concentration is heightened and his susceptibility to distrac- tion is decreased; when a reader plods along, his mind gets ahead of his eyes and he is an easy victim to all interruptions, especially to mind-wandering. The concentration attendant upon rapid reading is probably the reason for the superiority in comprehension tests of the fast reader to the slow reader. The idea that one reads slowly "to get more out of the reading" is demonstrably a myth. And since one of the purposes of libraries is to encourage more and better reading, they have a responsibility to utilize whatever proved methods are available.

When the library staff no longer needs the pacer and book of instructions, the reading room could be equipped with comfortable chairs and continued, according to the plan Mr. Muller has designed, as a room for staff reading. The pacer and instructions, meanwhile, need not go unused. They could profitably be placed in the main reading room for use by interested patrons of the library who are unable to secure class instruction in reading techniques. The device itself will attract attention and a poster nearby could explain the advantages of a few hours a week spent in the development of reading skills. A staff member could introduce the patron to the mechanics of the program and, incidentally, give a first-hand account of the effectiveness of the training. If the program proves popular, as it is likely to do, other facilities for training better readers may be added.

I believe that as the advantages of instruction and practice in efficient reading become better known, and as there are more graduates of developmental reading programs, more libraries will consider the facilities for improving reading abilities an indispensable part of their program to encourage more reading - and better reading. 